\title{
Caracterização da produtividade do funcho (Foeniculum vulgare Mill.) no sertão de Sergipe
}

\author{
CARVALHO, L.M. ${ }^{1 *}$;OLIVEIRA, I.R. ${ }^{1}$; CARNELOSSI, M.A.G. ${ }^{2}$; NUNES, R.S. ${ }^{2}$ \\ 1 EMBRAPA TABULEIROS COSTEIROS Av Beira mar 3250, CP. 44. 49025040 Aracaju-SE. \\ luciana@cpatc.embrapa.br. ${ }^{2}$. Universidade Federal de Sergipe-UFS. Centro de Ciências agrárias- Departamento de \\ Engenharia de Alimentos. Av Marechal Rondon s. n., 49100-000. São Cristóvão-SE. Brazilluciana@cpatc.embrapa.br, \\ ivenio@cpatc.embrapa.br, carnelossi@ufs.br, rogeriabr@hotmail.com
}

\begin{abstract}
RESUMO: Com o objetivo de avaliar a produtividade e qualidade do funcho (Foeniculum vulgare Mill.) produzido nas condições edafoclimáticas de Sergipe, foi conduzido cultivo orgânico de funcho em Frei Paulo-SE. Em junho de 2008 e de 2009, início do período de chuvas, foram instalados plantios por meio de mudas. Adicionalmente, em dezembro de 2010 foi realizada colheita de frutos a partir de plantas obtidas após poda drástica e rebrota. Foi realizada colheita de frutos e determinação da produtividade de dezembro a janeiro de 2008, 2009 e em dezembro de 2010. Verificou-se produtividade de $720 \mathrm{Kg}$. ha-1, no primeiro plantio e de $349 \mathrm{Kg}^{-h^{-1}}{ }^{-1}$ no plantio de 2009. As plantas obtidas por rebrota em 2010 resultaram em produtividade de $589 \mathrm{Kg}^{-h^{-1}}$. Sugere-se que a maior produtividade verificada no primeiro ano seja decorrente da maior precipitação média e conseqüente maior disponibilidade de água. A produtividade verificada nas plantas que rebrotaram em 2010 foi também superior a verificada em 2009, o que pode ser explicado tanto em função da maior precipitação, quanto em função do provável maior desenvolvimento das raízes e maior número de ramos após poda, devido à quebra da dominância apical. Esses dados sugerem importância da disponibilidade hídrica na determinação da produtividade na região e explicam a variação na produtividade verificada. A massa seca dos frutos (5, $29 \mathrm{~g}$ para 1000 frutos) e o alto teor de óleo essencial verificado $(3,2 \%)$, assim como a composição do óleo, revelam a alta qualidade dos frutos produzidos na região.
\end{abstract}

Palavras-chave: Erva-doce, plantas medicinais e aromáticas, agricultura orgânica.

\begin{abstract}
Characterization of the of fennel's (Foeniculum vulgare Mill.) yield semi-arid areas of Sergipe state. Aiming to evaluate the productivity and quality of fennel fruits produced in the countryside of Sergipe, with no irrigation, they were evaluated organic crops in Frei PauloSE. They were installed crops in 2008 and 2009 from seeds, on beginning rainy time. Seedlings obtained from seeds were transplanted in June 2008 and 2009. Besides, after the last harvest of the plants, grown in 2009, it was done a drastic pruning on plants, on May, 2010. The plants were held on the area until their fruits harvest, on december and January of 2008, 2009 and December 2010. The fennel fruits yield was $720 \mathrm{Kg} \mathrm{ha}^{-1}$ in the first crop (2008) and $349 \mathrm{Kg} \mathrm{ha}^{-1}$ at following crop (2009), while the fruits yield obtained from pruned plants was $589 \mathrm{Kg}$ ha $^{-1}$. It is suggested that the higher yield at the first year has been due to the higher average rainfall and its greater availability of water. The observed yield in sprouted plants was higher (at 2010) than fennel yield of 2009. It can be explained as a function of precipitation, likely as a function of greater root development and increased number of branches and umbels after pruning and breaking of apical. These results reveal water availability importance to fennel yield. The dried mass of fruits $(5.29 \mathrm{~g}$ to 1000 fruits), high content of essential oil in fruits (3.2\%) and the essential oil composition reveal good quality of fennel fruits of Sergipe.
\end{abstract}

Key words: Fennel, medicinal and aromatic plants, organic crop.

Recebido para publicação: agosto de 2011

Aceito para publicação: dezembro de 2011

Rev. Bras. Pl. Med., Botucatu, v.13, especial, p.527-532, 2011. 


\section{INTRODUÇÃO}

A atual estrutura agrária do Nordeste, com predomínio de minifúndios, está se tornando inviável para muitas atividades agropecuárias e demandando cada vez mais atividades com maior rentabilidade por área cultivada. A produção comercial de plantas medicinais, aromáticas e condimentares pode ser uma alternativa. Algumas ervas medicinais, como funcho (Foeniculum vulgare) e capim-santo (Cymbopogon citratus) tem sido cultivadas em algumas áreas do nordeste do Brasil. Em função das peculiaridades da forma de ocupação e uso da terra, esses cultivos ocorrem em áreas relativamente pequenas de agricultura familiar e com baixo uso de insumos.

É recente o valor econômico dado às ervas aromáticas, medicinais e condimentares no Brasil. O uso dessas ervas adquiriu grande importância nos últimos anos, devido a busca por vida mais saudável e o crescente interesse pelas ervas e fitoterápicos, especialmente após aprovação da Política Nacional de Plantas Medicinais e Fitoterápicos, em decorrência do reconhecimento da comprovada eficiência, pouco efeito colateral e baixo custo operacional. Aliado a isso, o interesse por essas ervas, como aromatizantes e condimentos naturais, cresce em todo o mundo em consonância com a busca por mais saúde e segurança alimentar. Os resultados do Censo Agropecuário do IBGE de 1996 e de 2006 comprovam isso. No Censo de 1996, o IBGE coletou informações, dentre as hortaliças, de produção apenas do agrião, cebolinha, coentro e salsa. No censo de 2006, além de verificar aumento de mais de $100 \%$ na produção das hortaliças, passou a contabilizar, no grupo das hortaliças, aipo, alecrim, alho-poró, bertalha, caruru, erva-doce, espinafre, hortelã, manjericão e orégano. Esse Censo revelou ainda que o funcho (ou erva-doce) destacase dentre as ervas mais valorizadas (maior preço) no país, junto com alho-porró e alecrim. Além disso, indicou que a Região Nordeste foi a segunda maior produtora de erva-doce, com $17,71 \%$ do total brasileiro, depois da Região Sudeste, que contribuiu com $81,19 \%$. Participaram da produção nordestina de erva-doce os estados de Sergipe $(9,85 \%)$, Bahia (4,56\%), Paraíba (2,57\%) e Pernambuco (0,73\%).

Funcho ou erva-doce-brasileira (Foeniculum vulgare Miller) é uma erva aromática, medicinal e condimentar da família Apiaceae. Possui caule estriado, de até $2 \mathrm{~m}$ de altura, folhas compostas pinadas, com folíolos reduzidos a filamentos, sendo maiores no estrato inferior da planta, com até $30 \mathrm{~cm}$ de comprimento, e mais estreitas, próximo ao ápice. As flores são pequenas, hermafroditas, de cor amarela, dispostas em umbelas compostas por 10 a 20 umbelas menores. Os frutos, oblongos e compostos por dois aquênios, constituem o órgão com maior teor de óleo essencial e mais utilizado. Na terapêutica é indicado, principalmente no alívio de problemas digestivos, para eliminar gases, combater cólicas e estimular lactação. Na culinária, os frutos, denominados popularmente de sementes, são utilizados para condimentar e aromatizar pães, bolos e biscoitos. Além disso, 0 óleo essencial é utilizado na cosmética e perfumaria (Lorenzi \& Matos, 2008).

É nativo na região Mediterrânea da Europa e da África, sendo também cultivado fora dessa área devido à grande adaptabilidade. É cultivado desde regiões onde o clima é ameno, ao nível do mar, até zonas tropicais com temperaturas mais elevadas, onde apresenta as melhores produções em termos de qualidade aromática e medicinal (Kapoor et al., 2004). Segundo literatura, há cultivos comerciais na França, Itália, Alemanha, Polônia, Rússia, China, Japão, Índia, Irã, Paquistão, Estados Unidos, Argentina e Brasil (Ahmad et al., 2004; Curado et al., 2007). No Brasil, foi introduzido pelos primeiros colonizadores europeus, sendo encontrado em jardins e hortas de norte a sul, em função da boa adaptação. No Brasil, há cultivo do funcho nos Estados da Bahia, Paraíba, Pernambuco e Sergipe há cerca de 50 anos, como alternativa complementar de renda, predominantemente, em regiões de transição entre agreste e sertão, em regime de sequeiro e de forma empírica, com adoção de poucas técnicas agronômicas. Os frutos são comercializados em feiras livres e mercados municipais, na forma de pequenos feixes ou molhos de umbelas por meio de atravessadores (Curado et al., 2007).

Atualmente, a China e a Índia dominam o mercado mundial: China exporta 0,12 milhões de tonelada, o que representa cerca de 300 milhões de dólares e a Índia comercializa 0,032 toneladas, totalizando cerca de 80 milhões de dólares (Ahmad et al., 2004). O Brasil exporta óleo de citrus e de eucalipto, mas ainda não tem expressão no comércio de óleos essenciais de ervas aromáticas. No entanto, tem condições de clima e de solo favoráveis ao desenvolvimento das ervas aromáticas. Essas plantas são de fácil cultivo e tem possibilidade de grande rentabilidade por área cultivada e possibilidade de cultivo em pequenas áreas, além de constituírem fonte alternativa de renda para os pequenos agricultores

Com a finalidade de determinar a produtividade do funcho nas condições edafoclimáticas do Estado de Sergipe foram conduzidos e avaliados cultivos experimentais orgânicos em área de Frei Paulo -SE em 2008 e 2009, em condições similares a praticada pelos agricultores familiares da região. 


\section{MATERIAL E MÉTODO}

Plantios de funcho (Foeniculum vulgareMiller) foram implantados, em regime de sequeiro, como é praticado na região, nos anos de 2008 e de 2009, sendo conduzidos ao longo de cerca de 180 - 220 dias em campo experimental da Embrapa, situado no município de Frei Paulo-SE. Além disso, em maio de 2010, após término das colheitas de frutos das plantas do segundo plantio de funcho e de capina para limpeza da área de plantio, foi realizada poda drástica nas plantas a fim de obter plantas por rebrota e verificar produção das mesmas no segundo ano do cultivo, como é tradicionalmente feito pelos pequenos agricultores da região. Com o material de estudo foi obtida excicata, que foi depositada no Herbáreo ASE, da Universidade Federal de Sergipe, sob o número 09052.

No entorno da área de produção foi instalado linha de cultivo de mandioca como barreira de vento. Aos 45 dias após semeadura, mudas de funcho com cerca de $12 \mathrm{~cm}$ de altura foram instaladas a campo, em covas espaçadas em 1,00 x 0,80 $\mathrm{m}$ ao longo de linhas de plantio com cerca de $7 \mathrm{~m}$ de comprimento. As mudas foram produzidas em bandejas de poliestireno expandido preenchidas com substrato comercial orgânico. A adubação de fundação foi realizada, ao longo das linhas de plantio, com base em análise química do solo, com esterco de ovinos decomposto e fosfato de rocha. Os plantios foram conduzidos por cerca de oito meses, sendo realizado em junho, início do período de chuvas, e encerrado em janeiro ou fevereiro, com o término da colheita. $O$ cultivo não foi irrigado, dependendo, portanto, apenas da precipitação para suprir suas necessidades hídricas. Em 2010, no período de chuvas, após poda drástica foi feito adubação de cobertura com esterco de ovino decomposto.

Dados de precipitação diários foram obtidos na área experimental, sendo a média de cada mês calculada e registrada (Tabela 1). O crescimento das plantas, em altura e em área de cobertura da "copa", foi determinado com trena, aos 60 e 120 dias após o plantio. A estimativa da área de cobertura das copas foi realizada, por meio da determinação das maiores dimensões em ângulo reto.

$\mathrm{Na}$ operação de colheita dos frutos, umbelas compostas foram destacadas por meio de tesoura de poda. Foram colhidas umbelas com diferentes teores de umidade, com coloração variando de verdeamarelado a amarelo-amarronzado. As umbelas foram acondicionadas em embalagens de papel pardo para serem conduzidas até o laboratório de plantas medicinais, onde foram submetidas à desidratação. A desidratação foi realizada em sala de secagem, escura, com temperatura ambiente em torno de $34^{\circ}$ e umidade relativa mantida em $40 \%$, por meio de desumidificador. Na sala, as umbelas foram uniformemente distribuídas nas bandejas teladas do secador de bandejas. Quando a umidade foi reduzida a $10 \%$, os frutos foram destacados dos pedicelos das umbelas e tiveram a massa seca determinada em balança de precisão. A produção de cada ano foi determinada com base na massa seca dos frutos colhidos a partir de trinta plantas e a produtividade, em quilos por hectare, foi estimada a partir dos dados de produção e da área de colheita. Além disso, determinou-se massa seca de 1000 frutos. Os frutos de funcho foram, posteriormente, acondicionados em embalagens de papel pardo e de polietileno e armazenados em freezer a $-18{ }^{\circ} \mathrm{C}$, enquanto aguardavam para serem submetidos à extração e determinação do teor de óleo essencial.

Para as análises de óleo essencial, os frutos foram moídos em micromoinho (Marconi, modelo MA630/1) e amostras com cerca de $50 \mathrm{~g}$ foram submetidas à hidrodestilação em Clevenger por duas

TABELA 1. Dados climáticos da área experimental, em Frei Paulo-SE, de janeiro a dezembro de 2008, 2009 e 2010. Climatic data of experimental Field, Frei Paulo-SE, since january of 2008 to december of 2010

\begin{tabular}{lccc}
\hline Mês & 2008 & Precipitação média $(\mathrm{mm})$ & 2009 \\
Janeiro & 34,93 & 26 & 81 \\
Fevereiro & 57,23 & 26 & 118 \\
Março & 85,42 & 26 & 94 \\
Abril & 127,87 & 25 & 231,5 \\
Maio & 184 & 24,5 & 85 \\
Junho & 141,13 & 22,5 & 195,5 \\
Julho & 115,87 & 21,8 & 178 \\
Agosto & 75,66 & 22 & 61 \\
Setembro & 63,76 & 23 & 98,5 \\
Outubro & 36,19 & 24,2 & 98 \\
Novembro & 36,1 & 25 & 0,3 \\
Dezembro & 39,09 & 25,7 & 0 \\
MEDIA ANUAL & 83,10417 & 24,30833 & 103,4 \\
\hline
\end{tabular}

Rev. Bras. PI. Med., Botucatu, v.13, especial, p.527-532, 2011. 
horas. Com os dados de volume de óleo extraído e massa utilizada determinou-se o teor de óleo essencial, o qual foi expresso em porcentagem. A composição do óleo essencial foi posteriormente determinada a partir dos frutos colhidos no cultivo de 2008. Foram feitas injeções de alíquotas de $1 \mathrm{~mL}$ do óleo, seco previamente com hidróxido de sódio e posteriormente diluído em hexano, em CG-MS Perkin Elmer, equipado com detector FID, tendo como gás de arraste $\circ \mathrm{N}_{2}$.

\section{RESULTADO E DISCUSSÃO}

Aos 60 dias após o plantio das mudas de funcho, as plantas tinham, em média, 0,66 $\mathrm{m}$ de altura e $0,43 \mathrm{~m}^{2}$ de área de cobertura de "copa". As plantas ainda estavam em crescimento vegetativo. Algumas plantas, no entanto, tinham iniciado o desenvolvimento do caule principal e central, a partir de onde as umbelas se formam. Em outubro, aos 120 dias após o plantio, a altura das plantas já havia aumentado, em média, para 1,77 m e a área de cobertura da copa, em média reduziu de $0,43 \mathrm{~m}^{2}$ para $0,33 \mathrm{~m}^{2}$, devido à mudança na arquitetura da planta, imposta pelo desenvolvimento do caule principal. A arquitetura das plantas tornou-se mais triangular. As plantas estavam no estádio reprodutivo, com as primeiras umbelas floríferas já emitidas. A produção de frutos foi iniciada em novembro, sendo a primeira colheita realizada em dezembro, por volta dos 180 dias após plantio das mudas a campo, quando a maioria das plantas já tinha frutos em ponto de colheita.

A massa de 1000 frutos secos, obtidos na área experimental de Frei Paulo em 2008 - 2009 e em 2009 - 2010 rendeu, respectivamente, 5,49 g e 6 g (Tabela 2). Valores similares foram obtidos por outros autores. Lopes et al. (2010) verificaram variação de 2,5 a 6,0 g na massa seca de 1000 frutos de funcho do Banco de Germoplasma de Portugal. Similarmente Bernath et al. (2005) encontraram variação entre 3,33 e $5,45 \mathrm{~g}$ na massa seca de frutos da Hungria, enquanto Bianco et al. (1994) encontraram variação de 2,8 a $4,7 \mathrm{~g}$ em frutos italianos. Com base nisso conclui-se que os frutos colhidos em Frei Paulo-SE no ano de 2008 tiveram massa similar aos frutos maiores colhidos em Portugal, Hungria e Itália. Segundo Lopes et al. (2010), frutos com menores massas são mais comuns em plantas espontâneas daqueles países.

No presente trabalho, a maior média de produtividade de frutos $\left(720 \mathrm{Kg} \mathrm{ha}^{-1}\right)$ foi obtida pelas plantas cultivadas no período de junho de 2008 a janeiro de 2009 (Tabela 2). Essa produtividade foi superior a descrita por Ahmad et al. (2004) para cultivos de funcho conduzidos no Paquistão com espaçamentos entre plantas de $0,40 \mathrm{~m}(560,5 \mathrm{Kg}$ ha1) e 0,70 m (192,5 Kg ha-1). Oliveira (2009) em estudo de sistemas de produção de erva-doce, instalados no agreste da Paraíba, verificou, na presença de irrigação por aspersão, produção de funcho de 62,75 $\mathrm{kg} \mathrm{ha}^{-1}$, portanto bem abaixo da produtividade alcançada no presente trabalho em ambas as áreas experimentais sem irrigação.

Comparando-se as médias de produtividade obtidas pelas plantas do primeiro cultivo (conduzido de junho de 2008 a janeiro de 2009) e do segundo cultivo (conduzido de junho de 2009 a janeiro de 2010), verificou-se que as médias do primeiro cultivo (720 $\left.\mathrm{kg} \mathrm{ha}^{-1}\right)$ foram muito superiores a do segundo $(349 \mathrm{~kg}$ $\left.\mathrm{ha}^{-1}\right)$. Sugere-se que essa diferença seja decorrente, principalmente, da maior disponibilidade de umidade no solo, propiciada pela maior precipitação verificada no primeiro plantio (Tabela 1). A precipitação no ano de 2008 foi, em todos os meses, superior a de 2009, especialmente no período de estabelecimento e crescimento vegetativo das plantas. Quanto à importância da irrigação para a produtividade do funcho, Buntain e Chung (1994) verificaram, nas condições de verão seco da Tasmânia, aumento no número de umbelas, na massa seca das sementes, e consequentemente na produtividade das plantas com o aumento da disponibilidade de água de irrigação.

Comparando-se a produtividade de frutos do segundo plantio ( $\left.349 \mathrm{~kg} \mathrm{ha}^{-1}\right)$ de funcho com os dados obtidos a partir das mesmas plantas após a poda e rebrota no ano seguinte (589 kg ha-1) verificou-se aumento na produtividade (Tabela 2). Segundo os agricultores familiares de Simão Dias, principal local de produção em Sergipe (Curado et al., 2007 ) a

TABELA 2. Médias de produtividade ( $\left.\mathrm{Kg} \cdot \mathrm{ha}^{-1}\right)$ e de teor de óleo essencial obtido a partir de plantas de funcho cultivadas em Frei Paulo-SE, em condição de sequeiro, nos anos de 2008 e 2009 e 2010, após poda e rebrota. Mean yield $\left(\mathrm{Kg} \mathrm{ha}^{-1}\right)$ and essential oil content of fennel plants grown in Frei Paulo-SE on 2008, 2009 and 2010, after pruning

\begin{tabular}{llll}
\hline Variável & \multicolumn{3}{c}{ Frei Paulo } \\
& 2008 & 2009 & 2010 \\
Produtividade de frutos $\left(\mathrm{Kg}_{\mathrm{N}} \mathrm{ha}^{-1}\right)$ & 720 & 349 & 589 \\
Peso de 1000 sementes $(\mathrm{g})$ & 5,49 & 6,00 & $*$ \\
Teor médio de óleo essencial $(\%)$ & 3,20 & 2,99 & 3,59 \\
\hline
\end{tabular}

* Não foi determinado peso de 1000 sementes no experimento de 2010

Rev. Bras. Pl. Med., Botucatu, v.13, especial, p.527-532, 2011. 
produção do segundo ano de cultivo, ou seja das plantas obtidas por meio de rebrota é sempre maior. Sugere-se que esse resultado seja decorrente da quebra da dominância apical imposta pela poda drástica e conseqüente produção de maior número de ramos laterais e consequentemente maior número de umbelas e frutos por planta e ainda da condição do sistema radicular, que no segundo caso já está plenamente desenvolvido e com condições maiores, portanto, de obter água e nutrientes a partir do solo. Além disso, deve-se considerar que há uma tendência cíclica de anos secos seguidos de anos mais chuvosos, como se verificou no período de 2008 a 2010 (Tabela 1).

Comparando-se os teores de óleo essencial (Tabela 2) obtidos a partir dos cultivos de 2008 (3,2 $\%$ ) e de 2009 (2,99\%) em Frei Paulo-SE, verificouse que a maior precipitação média (Tabela 1), verificada no primeiro ano (2008), contribuiu pouco com o aumento do teor de óleo dos frutos. No entanto, após a poda e rebrota das plantas, realizada em 2010, verificou-se maior aumento no teor de óleo, de 2,99 $\%$ de óleo no primeiro ciclo para $3,59 \%$, no segundo ciclo de cultivo das mesmas plantas (Tabela 2). Com isso infere-se que o aumento no teor de óleo nas plantas entre os cultivos de 2009 e 2010 provavelmente não decorreu apenas da maior precipitação e consequente maior disponibilidade de água no solo. Seria interessante, em estudos posteriores, caracterizar e dimensionar o sistema radicular das plantas do primeiro e segundo ciclo consecutivos, a fim de buscar explicações para a alteração na produtividade e teor de óleo essencial.

No óleo essencial do funcho cultivado em Frei Paulo-SE se verificou presença dos componentes principais e marcadores: Anetol, funchol e metilchavicol (Tabela 3), com quantidades similares de anetol e metil-chavicol. Dessa forma determinou-se a qualidade do óleo obtido nessa região.

Conclui-se que a maior disponibilidade de umidade, verificada em 2008 e em 2010, favoreceu maior produtividade e teor de óleo essencial nos frutos nas condições edafoclimáticas do semi-árido sergipano estudadas. Além disso, a manutenção das plantas por até dois anos consecutivos na mesma área, por meio de poda drástica também contribuiu para o aumento verificado na produtividade e teor de óleo essencial. Com base nisso, constata-se, que ao menos por dois anos consecutivos, a prática dos agricultores de manter as plantas cultivadas no campo é vantajosa do ponto de vista da produtividade. No entanto, há de se considerar necessidade de adubação de cobertura após poda e de se ter cuidados na condução devido a maior possibilidade de ocorrência de pragas em função da permanência da planta na mesma área por mais tempo. Além disso, com a poda drástica, verificou-se redução no stand,
TABELA 3. Dados médios de composição do óleo essencial de frutos de funcho (Foeniculum vulgare Mill), cultivados no semi-árido sergipano, em condição de sequeiro de junho de 2008 a janeiro de 2009 . Average data of composition of essential oil obtained from the fruits of fennel (Foeniculum vulgare Mill.) grown in semi-arid of Sergipe state, with no irrigation, from June, 2008 to January, 2009

\begin{tabular}{l|c}
\hline Componente & Volume (\%) \\
\hline Estilboestrol & 2,24 \\
\hline$\alpha$-pineno & 3,35 \\
\hline Limoneno & 2,37 \\
\hline Metil-chavicol & 24,5 \\
\hline$(\alpha)$-anetol & 25,23 \\
\hline Anisaldeído & 0,10 \\
\hline Linalol & 6,48 \\
\hline Neral & 2,24 \\
\hline Geranial & 3,45 \\
\hline 4-terpineol 1 & 11,92 \\
\hline Oxido de cariofileno & 5,04 \\
\hline Funchona & 13,08 \\
\hline Total & 100,00 \\
\hline
\end{tabular}

com a perda de algumas plantas na área de plantio, o que indica necessidade de cuidado e atenção na poda, das mesmas, a fim de evitar desuniformidade na área de produção. Quanto à qualidade aromática dos frutos, a massa seca dos mesmos (5, $29 \mathrm{~g}$ para 1000 frutos) e o alto teor de óleo essencial verificado (3,2\%), além da composição do óleo, indicam a boa qualidade dos frutos produzidos na região.

\section{REFERÊNCIA}

AHMAD, M, HUSSAIN, SA, ZUBAIR, M, RAB, A. Effect of diffeent sowing seasons and row spacing on seed production of fennel. Pakistan Journal of Biological Sciences, 7, 1144-1147, 2004.

BERNATH, J, NEMETH, E, HANNIG, JH, NEYE, O. Up to date results in selection and registration of "small seeded" cultivars of Foeniculum vulgare Mill. For large scale production. Acta Horticulturae, 675, 191-196, 2005. CURADO, F. F.; NUNES, M. U. C.; CARVALHO, L. M.; OLIVEIRA, I. R.; RODRIGUES, R. F. A. Experimentação participativa na produção de erva-doce (Foeniculum Vulgare Mill.) em bases ecológicas. Aracaju: Embrapa Tabuleiros Costeiros, 2007.19 p. (Documentos / Embrapa Tabuleiros Costeiros, 110). Disponível em http://<www.cpatc.embrapa.br> ISBN 1678-1953. Acesso em : 15 de agosto (15/08) 2011.

IBGE. Censo Agropecuário. IBGE- Sistema IBGE de Recuperação automática - SIDRA. Disponível em www.ibge.gov.br/home/.../agropecuario/censoagro/.../ agropecuario.pdf. Acesso em: agosto de 2011.

LORENZI, H.; MATOS, FJA. Plantas medicinais no Brasil: nativas e exóticas. 2 ed. Nova Odessa, SP.: Instituto 
Plantarum, 2008. $576 \mathrm{p}$

LOPES, VR; BARATA, AM, FARIAS, R., MENDES, MD, LIMA, AS, PEDRO, LG, BARROSO, JG, FIGUEIREDO, AC. Morphological and essential oil variability from nine portuguese fennel (Foeniculum vulgare Mill.) accessions. Acta Horticulturae, 860, 33-49, 2010.
OLIVEIRA, F. J. V. Produtividade de erva-doce (Foeniculum vulgare Mill.) em função do parcelamento da adubação orgânica e mineral e sistemas de cultivo. 2009. 93p. Tese (Doutorado - Área de Concentração em Agronomia). Centro de Ciências Agrárias, Universidade Federal da Paraíba, Areia. 